\title{
Competências habilitadoras da melhoria contínua: estudo de casos em empresas do setor automobilístico e de bens de capital
}

\section{Continuous improvement enabling competences: case studies in companies in the automotive sector and capital goods}

\author{
Rodrigo Valio Dominguez Gonzalez ${ }^{1}$ \\ Manoel Fernando Martins ${ }^{2}$
}

\begin{abstract}
Resumo: O estado atual da arte sobre melhoria contínua leva em consideração que as competências e comportamentos organizacionais são elementos mais importantes para a condução e sustentabilidade do que os aspectos de ordem técnica. Este conjunto de competências e comportamentos, inicialmente tratados por Bessant e Caffyn na década de 90, considera, essencialmente, que as organizações devem construir um ambiente voltado à aprendizagem contínua. Desta forma, este artigo tem como objetivo principal analisar o desenvolvimento das competências que sustentam os programas de melhoria contínua em dois ambientes produtivos distintos: setor automobilístico e de bens de capital sob encomenda. A partir de um referencial teórico sobre o tema, é levantado um conjunto de competências que é relacionado à prática da melhoria contínua e, por meio de uma abordagem qualitativa, são analisadas quatro empresas dos dois setores considerados, utilizando-se uma estratégia de estudo de casos. Os resultados da pesquisa sugerem que as empresas do setor automobilístico pesquisadas apresentam maior nível de envolvimento dos funcionários em relação aos programas de melhoria contínua, quando comparadas às empresas do setor de bens de capital, que se justifica pela estratégia adotada pelas organizações.
\end{abstract}

Palavras-chave: Melhoria contínua; Competências; Aprendizagem; Setor automobilístico; Setor de bens de capital.

\begin{abstract}
The current state of the art on continuous improvement takes into account that the organizational competences and behaviors are more important elements for continuous improvement sustainability than the technical aspect. This set of competences and behaviors, initially treated by Bessant and Caffyn in the 90s, essentially considers that companies must build an environment geared to ongoing learning. Thus, this paper aimed to analyze the development of competences that support the continuous improvement in two different production environments: the automotive and capital goods to order industry. A set of competences that is related to the practice of continuous improvement is raised based on a theoretical background, and through a qualitative approach, four companies of the two considered sectors are analyzed. The research results suggest that the researched automotive sector companies have higher level of employee engagement in continuous improvement programs compared to companies in the capital goods sector, which is justified by the strategy adopted by the them.
\end{abstract}

Keywords: Continuous improvement; Competences; Learning; Automotive industry; Capital goods industry.

\section{Introdução}

Visando aumentar o nível de competitividade em mercados cada vez mais globalizados, as organizações necessitam considerar estratégias que promovam a melhoria contínua de seus processos produtivos. A necessidade de inovação e melhoria contínua tem direcionado a discussão de fábrica como "laboratório" (Gonzalez \& Martins, 2007) ou aquilo que Jochem et al. (2012) e Bessant et al. (2001) denominam de organização de aprendizagem.

Vários atributos são relacionados a este tipo de manufatura como o papel dos trabalhadores de chão de fábrica, a capacidade dos indivíduos em compartilhar e aplicar o conhecimento para solução de problemas e continuamente melhorar, a receptividade

\footnotetext{
${ }^{1}$ Universidade Estadual de Campinas - UNICAMP, Rua Pedro Zaccaria, 1300, CEP 13484-350, Limeira, SP, Brasil, e-mail: rodrigo.gonzalez@fca.unicamp.br

${ }^{2}$ Universidade Federal de São Carlos - UFSCar, Rodovia Washington Luís, Km 235, SP 310, CEP 13565-905, São Carlos, SP, Brasil, e-mail: manoelf@dep.ufscar.br
} 
dos indivíduos em relação às mudanças propostas, o trabalho em equipe e a autonomia (Jochem et al., 2012; Gonzalez \& Martins, 2007).

Bessant \& Caffyn (1997) definem melhoria contínua como sendo um processo empresarial de evidente e intermitente inovação incremental com a utilização de poucos recursos, não se diferenciando dos conceitos apresentados por outros autores.

É evidente, em diversas organizações, que existe um consenso em relação à necessidade de mudar e melhorar constantemente seus processos a fim de atender às exigências dos clientes. Contudo, percebe-se que muitos programas de melhoria enfatizam apenas o lado técnico, não se atentando à necessidade de uma revolução comportamental que tal prática exige (Lam et al., 2015; Ali et al., 2013). Assim, quando não sustentados pelos elementos que caracterizam a organização de aprendizagem, os programas de melhoria acabam não apresentando os resultados esperados.

Tendo em vista que a melhoria contínua é dependente de um contexto organizacional favorável à sua prática, esta pesquisa considera dois setores que apresentam contextos produtivos distintos. O primeiro trata-se do setor automobilístico, que possui processos produtivos mais constantes, isto é, não há necessidade do redesenho do processo a cada novo produto lançado. $\mathrm{O}$ segundo setor pesquisado é o de bens de capital sob encomenda. As empresas deste setor atuam com grandes variações dos produtos, implicando uma atividade constante de projeto de produto e processo (Vermulm \& Erber, 2002). Desta forma, este artigo tem como objetivo principal mapear as competências que sustentam a prática da melhoria contínua em empresas do setor automobilístico e de bens de capital. Além disso, como objetivo secundário, o artigo analisa as diferenças quanto ao desenvolvimento destas competências nas empresas dos dois setores pesquisados.

\section{Melhoria contínua}

A melhoria contínua pode ser definida como um processo de inovação incremental, focada e contínua, envolvendo toda a organização (Bessant et al., 1994). Seus pequenos passos, alta frequência e pequenos ciclos de mudanças vistos separadamente têm pequenos impactos, mas somados podem trazer uma contribuição significativa para o desempenho da empresa (Jaca et al., 2012; Wu \& Chen, 2006).

O modelo japonês que trata a melhoria contínua com a participação de todos os funcionários de diferentes níveis hierárquicos é denominado kaizen. Apesar de enfatizar melhorias pequenas, ele traz resultados significativos ao longo do tempo (Imai, 1997).

O kaizen gerou uma forma particular de pensar voltada para o processo e um sistema administrativo que apoia e reconhece os esforços para o melhoramento
(Gonzalez \& Martins, 2011; Ali et al., 2013). Por meio desse conceito, os funcionários passam a incorporar a melhoria contínua às suas rotinas de trabalho. A autonomia concedida aos funcionários é um fator de motivação para a prática e desenvolvimento das atividades de melhoria.

Diversos autores como Bateman (2005), Ali et al. (2013) e Jager et al. (2004) destacam a importância de as organizações focarem a implementação da melhoria contínua, desenvolvendo cultura e estrutura interna que fomente sua prática, ao invés de apenas dar ênfase às ferramentas e técnicas de solução de problemas. O kaizen enfatiza o esforço humano, a moral, a comunicação, o treinamento, o trabalho em equipe, o envolvimento e a disciplina. Deste modo, esse processo exige comprometimento e envolvimento da alta administração, realizado de forma constante para assegurar seu sucesso (Lam et al., 2015).

A implantação da melhoria contínua, desta forma, deve levar em conta o desenvolvimento de uma cultura para melhoria contínua, que vise eliminar os desperdícios em todos os processos, envolvendo todos os funcionários, sem necessariamente fazer enorme dispêndio financeiro (Jaca et al., 2012; Bhuiyan \& Baghel, 2005).

A aprendizagem organizacional pode ser considerada o melhor caminho para uma empresa manter de forma sustentável a prática da melhoria contínua (Jochem et al., 2012; Bessant \& Caffyn, 1997; Gonzalez \& Martins, 2011; Kaye \& Anderson, 1999). Por meio da aprendizagem contínua dos indivíduos, a organização pode vencer a cultura voltada a "apagar incêndios", tornando a melhoria uma rotina (Teare \& Monk, 2002). A Figura 1 ilustra como uma empresa pode superar o problema de reagir aos problemas ("apagar incêndios") por meio de aprendizado contínuo.

O modelo utiliza a aprendizagem como fator fundamental na criação de uma organização dinâmica, que melhora continuamente, porém mantendo uma estabilidade interna. Para os autores, os dois tipos de organização, que "apaga incêndios" e que melhora continuamente, são dinâmicas. O diferencial entre elas está no fato de que as primeiras se caracterizam pela instabilidade interna e, em contrapartida, as segundas possuem uma estrutura estável.

O desenvolvimento de programas de melhoria contínua deve vir acompanhado de uma infraestrutura organizacional de execução e coordenação destas atividades (Bateman, 2005; Choo et al., 2007). Muitas organizações implantam seus programas de melhoria focando apenas a execução de projetos ad hoc (Gonzalez \& Martins, 2011; Teare \& Monk, 2002; Anand et al., 2009), usando ferramentas e técnicas conhecidas e consolidadas na área de melhoria da qualidade. Entretanto, estas organizações ignoram o conteúdo mais estratégico desses programas referente à coordenação e apoio das iniciativas de melhoria 
contínua (Ali et al., 2013). Este segundo grupo de atividades trata das atividades seleção e revisão de projetos, treinamento e motivação dos funcionários, preservação e disseminação das lições aprendidas (Anand et al., 2009). Algumas pesquisas realizadas por Choo et al. (2007) e Wruck \& Jensen (1998) revelam que os programas de melhoria contínua, quando não são apoiados por adequadas atividades de coordenação e suporte, perdem efetividade depois de conquistar ganhos iniciais.

O trabalho de Bessant \& Caffyn (1997) expõe um modelo de estágios evolucionários que as organizações atravessam em relação à prática da melhoria contínua (Figura 2). Em linha com Jurburg et al., 2015, Anand et al. (2009) e Choo et al. (2007), o modelo evolucionário de Bessant \& Caffyn (1997) apresenta em suas fases iniciais pouca ênfase sobre a coordenação da melhoria contínua.
O modelo é composto de cinco fases, sendo que nas fases 1 e 2 (pré-melhoria contínua e melhoria contínua estruturada), as ações de melhoria são voltadas para a execução de projetos ad hoc. Nos estágios 3 e 4, denominados de melhoria contínua orientada por metas e melhoria contínua proativa e autônoma, respectivamente, percebe-se a inclusão de características organizacionais de coordenação destas atividades.

Assim, a partir do estágio 3, os funcionários direcionam suas ações de melhoria para atender às demandas estratégicas da empresa; e, no estágio 4, os funcionários possuem maturidade e responsabilidade suficientes para desenvolverem atividades de melhoria de forma autônoma.

O estágio 5 ocorre quando a organização possui completa competência para a melhoria contínua, e denomina-se de organização de aprendizagem. Nesta fase, além das características descritas nos

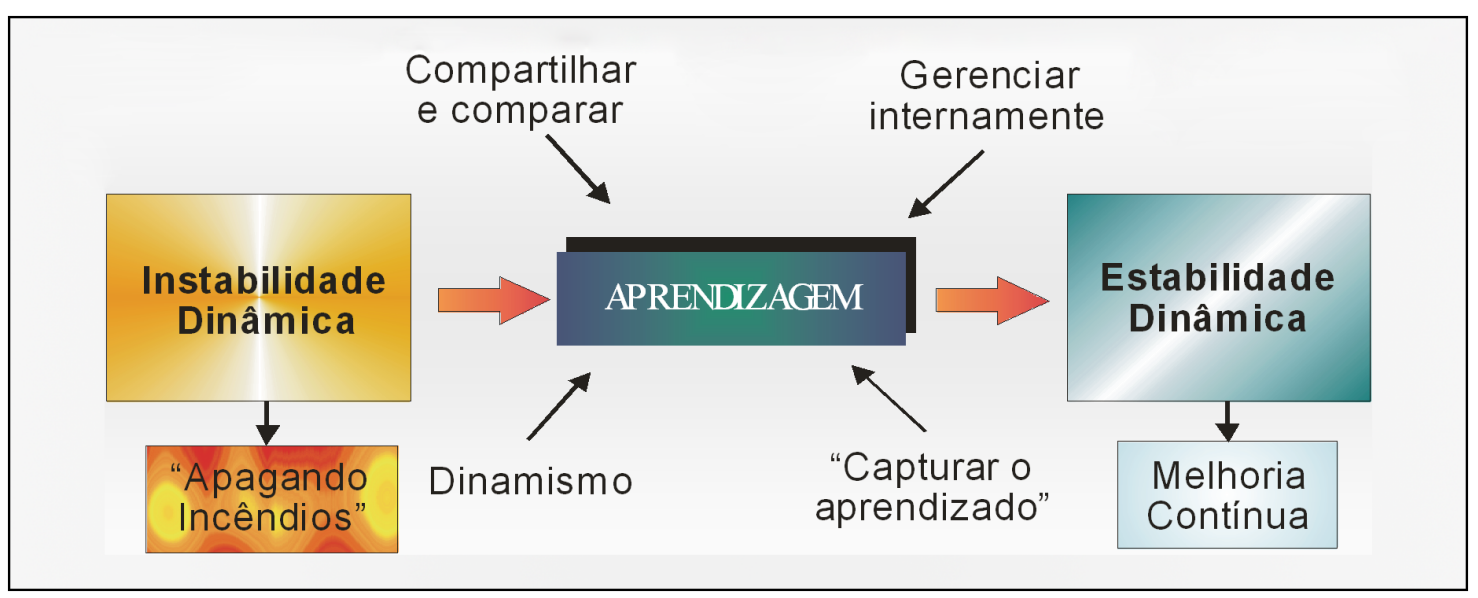

Figura 1. Aprendizagem como fonte de estabilidade dinâmica. Fonte: Teare \& Monk (2002).

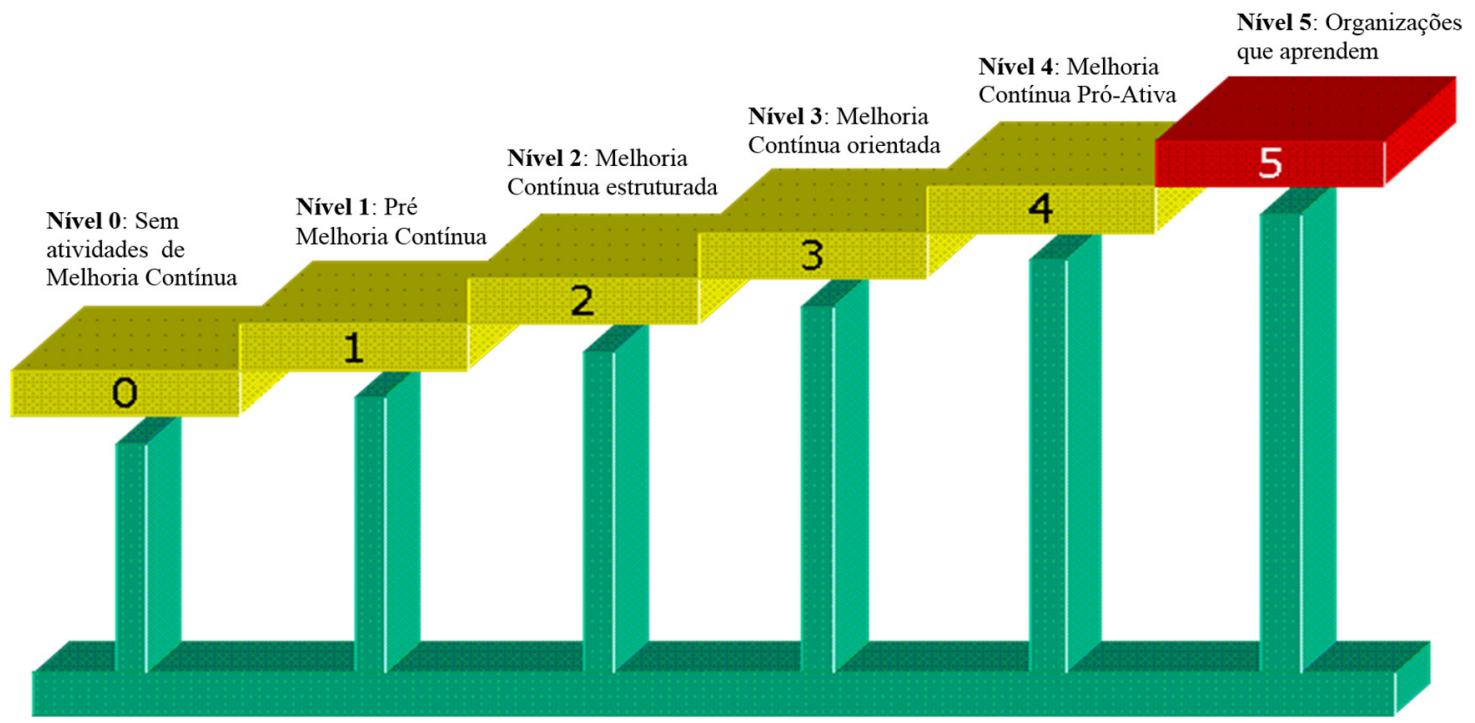

Figura 2. Estágios evolucionários da melhoria contínua. Fonte: Bessant \& Caffyn (1997). 
estágios anteriores, a organização possui competência para resgatar e compartilhar o aprendizado dos indivíduos e grupos, originado de iniciativas de inovação incremental e radical, num ambiente de amplo envolvimento das pessoas (Lam et al., 2015; Jurburg et al., 2015; Jaca et al., 2012; Bessant \& Caffyn, 1997).

Segundo Caffyn (1999), as competências relacionadas à melhoria contínua podem ser definidas como o conjunto de habilidades que permitem uma organização obter vantagem competitiva por meio da inovação incremental, contando com a participação significativa de seus membros. Muitas destas competências tratadas por Caffyn (1999) são de difícil implementação por conta da dificuldade que as organizações apresentam de romperem seus hábitos tradicionais e motivarem seus empregados a modificarem e adaptarem seus comportamentos (Bateman, 2005; Bhuiyan \& Baghel, 2005). Assim, a resistência à mudança deve ser vista como um agente que tende a retardar e prejudicar a implementação de iniciativas voltadas à melhoria contínua (Jurburg et al., 2015).

O melhor entendimento por parte dos funcionários acerca de como a melhoria contínua contribui para o cumprimento da missão e estratégia da organização aumenta a chance de sucesso (Ali et al., 2013).

\section{Método de pesquisa}

Com o objetivo de entender a maneira como as empresas de dois setores distintos organizam seus programas de melhoria contínua, é utilizada uma abordagem de pesquisa qualitativa, pois além das variáveis (melhoria contínua e características organizacionais) serem de difíceis mensurações, é necessária a presença do pesquisador em campo, no sentido de captar e entender o contexto no qual se inserem as variáveis pesquisadas (Bryman, 1989).
Além dos setores em que as empresas atuam, isto é, bens de capital e automobilístico, o processo de seleção das organizações participantes da pesquisa levou em consideração dois aspectos principais. $\mathrm{O}$ primeiro refere-se à implantação de um programa de melhoria contínua há pelo menos dois anos. É fundamental para a pesquisa que a empresa já tenha implementado as iniciativas voltadas para a melhoria contínua em um período de tempo considerado suficiente para que este programa esteja consolidado dentro da estrutura e cultura organizacional.

O segundo aspecto considerado para seleção das organizações refere-se ao porte das empresas. Foram consideradas apenas empresas de médio e grande porte pelo fato de que questões como envolvimento dos funcionários, interação funcional e fluxo de conhecimento ocorrem de forma bastante distinta em função do tamanho da organização.

O pesquisador entrou em contato com um total de 25 empresas do setor automobilístico e 21 empresas do setor de bens de capital. Em relação às empresas do setor automobilístico, cinco empresas se disponibilizaram em participar da pesquisa; enquanto no setor de bens de capital, a aceitação por parte das organizações foi de 4 empresas. Nas empresas que aceitaram participar da pesquisa, foi realizada uma entrevista inicial com seus respectivos gerentes de qualidade ou gerentes de produção a fim de se compreender o estágio de implantação de seus respectivos programas de melhoria. Em função desta entrevista inicial, foram selecionadas duas empresas de cada setor para participação da pesquisa. A Tabela 1 resume as principais características das empresas pesquisadas.

Depois da definição dos objetivos que guiam a pesquisa, bem como seu planejamento, no que se refere à definição do perfil das organizações participantes da pesquisa, Yin (2002) recomenda os seguintes passos para a condução do estudo de

Tabela 1. Caracterização das empresas pesquisadas.

\begin{tabular}{|c|c|c|c|c|}
\hline Dados das empresas & $\mathbf{A}$ & B & $\mathbf{C}$ & D \\
\hline Origem & Alemã & Francesa & Brasileira & Francesa \\
\hline Localização & Região de Campinas & Vale do Paraíba & Região de São Carlos & Grande São Paulo \\
\hline Tempo de atuação & 12 anos & 9 anos & 35 anos & 54 anos \\
\hline \multicolumn{5}{|l|}{$\begin{array}{l}\text { Tempo de implantação do } \\
\text { programa de melhoria }\end{array}$} \\
\hline Setor & Automobilístico & Automobilístico & Bens de capital & Bens de capital \\
\hline Funcionários & 860 & 590 & 1200 & 900 \\
\hline Faturamento anual (R\$) & 285milhões & 80milhões & 200 milhões & 100 milhões \\
\hline Produtos fabricados & $\begin{array}{l}\text { Chassis, eixos e para- } \\
\text { choques automotivos }\end{array}$ & $\begin{array}{l}\text { Sistemas de escape } \\
\text { automotivos }\end{array}$ & $\begin{array}{l}\text { Caldeiraria, extração } \\
\text { de petróleo e } \\
\text { distribuição de } \\
\text { energia }\end{array}$ & Painéis industriais \\
\hline Porte dos clientes & Grande porte & Grande porte & Grande porte & Grande porte \\
\hline
\end{tabular}


caso: definição do procedimento de coleta de dados e análise dos dados, conforme as seções seguintes.

\subsection{Coleta de dados}

A coleta dos dados presentes neste artigo foi desenvolvida durante um período de quatro meses. $\mathrm{O}$ procedimento de estudo de caso disponibiliza diferentes meios de coleta de dados. Esta pesquisa foi guiada pela observação direta, entrevistas e verificação de documentação (Yin, 2002).

Em relação à observação direta, para cada empresa pesquisada, o pesquisador focou a atenção sobre uma linha de produção específica, indicada pelo gerente de produção ou gerente de qualidade que intermediou a pesquisa. Nesta linha de produção indicada, o pesquisador coletou dados referentes ao desenvolvimento operacional dos programas de melhoria contínua, verificando os seguintes aspectos:

- O envolvimento dos funcionários da linha de produção com as atividades de melhoria;

- A forma como os funcionários se organizam em grupos para realização de melhoria;

- As ferramentas e métodos voltados para a melhoria utilizados pelo grupo;

- As habilidades técnicas, gerenciais e de relacionamento dominadas pelos indivíduos;

- O grau de interação entre os participantes do grupo;

- O relacionamento entre os participantes do grupo e a gerência.

Quanto às entrevistas, elas foram de características semiestruturada e não estruturada. Foram entrevistados funcionários de diferentes níveis e funções da organização. $\mathrm{Na}$ empresa $\mathrm{A}$, foram entrevistados 8 funcionários de chão de fábrica (operadores de máquina, técnico de manutenção e inspetores da qualidade), 1 supervisor de produção, o gerente de qualidade e o gerente de recursos humanos. Na empresa $\mathrm{B}$, participaram da entrevista 5 funcionários de chão de fábrica (operadores e facilitador de produção), o gerente de melhoria contínua e o diretor de produção. $\mathrm{Na}$ empresa $\mathrm{C}$, foram entrevistados 6 funcionários de chão de fábrica (operadores de produção), o gerente de qualidade e o gerente de produção. E, por fim, na empresa $\mathrm{D}$, participaram da entrevista 5 funcionários de chão de fábrica (operadores de produção e técnicos em manutenção), 1 supervisor de produção e o diretor de qualidade. A Tabela 2 expõe o perfil dos funcionários entrevistados e o tipo de questionário utilizado.

As entrevistas não estruturadas foram utilizadas com o pessoal operacional e supervisores, durante o período de observação direta. O pesquisador realizou três visitas em cada empresa. Nestas entrevistas, foram extraídas informações sobre o grau de entendimento e participação dos funcionários em relação aos programas de melhoria contínua, as técnicas para melhoria contínua, dominadas pelos indivíduos, e a motivação destes em participar destas atividades. O questionário semiestruturado foi aplicado aos funcionários do nível de gerência e direção e tratou dos seguintes aspectos:

- Parte A - Características gerais da empresa, apresentadas na Tabela 1.

- Parte B - Características dos programas de melhoria contínua: histórico dos programas; o formato de gestão dos programas; o envolvimento gerencial e dos funcionários dos diferentes níveis hierárquicos; os principais métodos e ferramentas utilizadas para a melhoria da qualidade; o foco dos programas de melhoria.

- Parte C-Competências habilitadoras da melhoria contínua (Tabela 3).

Tabela 2. Perfil dos entrevistados e instrumento de coleta utilizado.

\begin{tabular}{lll}
\hline Empresa & \multicolumn{1}{c}{ Questionário não estruturado } & Questionário semiestruturado \\
\hline A & -8 funcionários de chão de fábrica (operadores de máquina, & -1 gerente de qualidade; \\
& técnico de manutenção e inspetores da qualidade); & -1 gerente de recursos humanos. \\
& -1 supervisor de produção. & \\
B & -5 funcionários de chão de fábrica (operadores de & -1 gerente de melhoria contínua; \\
& produção); & -1 diretor de produção. \\
& -1 facilitador de produção. & -1 gerente de qualidade; \\
C & -6 funcionários de chão de fábrica (operadores de & -1 gerente de produção. \\
& produção). & \\
D & -5 funcionários de chão de fábrica (operadores de produção & -1 diretor de qualidade. \\
& e técnicos em manutenção); & \\
& -1 supervisor de produção.
\end{tabular}


Tabela 3. Competências que sustentam a melhoria contínua avaliada nos casos.

\section{Competências que sustentam Descrição a melhoria contínua}

Entendimento das metas organizacionais

Os funcionários devem compreender a estratégia organizacional a fim de alinharem suas ações de melhoria (Jurburg et al., 2015). Caso não haja um alinhamento estratégico, as ações de melhoria não passam de projetos ad hoc (Anand et al., 2009; Choo et al., 2007) ou ações de 'combate ao incêndio' (Teare \& Monk, 2002).

Sistema de gestão estruturado para a melhoria contínua.

Apoio e envolvimento gerencial

Envolvimento dos funcionários A melhoria contínua caracteriza-se por ações incrementais de pequeno passo e, desta forma, exige grande participação dos funcionários a fim de se obter desempenho significativo (Lam et al., 2015; Wu \& Chen, 2006; Bessant et al., 1994, 2001).

Melhoria desenvolvida em grupo

Os problemas tratados nas ações de melhoria, normalmente, são de ordem multidisciplinar. Portanto, o trabalho em grupo pode trazer a complementariedade de competências necessárias à resolução de problemas (Jaca et al., 2012; Irani et al., 2004).

Autonomia para a prática da melhoria

Desenvolvimento de competências dos indivíduos

Cultura voltada para melhoria contínua

Aprendizagem

Compartilhamento do conhecimento

Interação intraorganizacional

Os programas de melhoria devem ser apoiados por uma infraestrutura de coordenação no que se refere à seleção e revisão de projetos, treinamento e motivação de funcionários e resgate e disseminação das lições aprendidas (Ali et al., 2013; Anand et al., 2009; Bateman, 2005; Choo et al., 2007).

A direção da organização deve liderar o processo de implantação e condução dos programas de melhoria contínua (Lam et al., 2015; Jurburg et al., 2015; Bateman, 2005; Bhuiyan \& Baghel, 2005; Imai, 1997; Irani et al., 2004).

Os indivíduos e grupos de trabalho devem apresentar proatividade para propor e experimentar uma ação de melhoria (Bessant et al., 1994, 2001; Bessant \& Caffyn, 1997) e a autonomia é um aspecto motivador.

Os indivíduos devem apresentar competências suficientes para resolverem problemas de seus processos (Irani et al., 2004).

A cultura voltada para a melhoria contínua é definida como o conjunto de crenças e valores que dirigem os indivíduos da organização a apresentarem insatisfação contínua com o estado atual de seus processos, buscando o aperfeiçoamento destes (Jurburg et al., 2015; Bateman, 2005; Bhuiyan \& Baghel, 2005; Jager et al., 2004). Além disto, o ambiente organizacional orientado por esta cultura estimula e valoriza o compartilhamento do conhecimento entre os indivíduos (Gonzalez \& Martins, 2011; Bessant et al., 1994, 2001; Anand et al., 2009).

A melhoria contínua pode ser caracterizada por um processo de constante aprendizado. Assim, em cada iniciativa de melhoria, os indivíduos e grupos passam por um processo de pesquisa, experimentação e tentativa e erro, que gera novos conhecimentos (Gonzalez \& Martins, 2011; Jurburg et al., 2015; Jochem et al., 2012; Anand et al., 2009; Jager et al., 2004; Teare \& Monk, 2002; Bessant et al., 1994, 2001).

$\mathrm{O}$ conhecimento adquirido durante as iniciativas de melhoria deve ser resgatado e disseminado entre os indivíduos a fim de gerar novas ações de melhoria (Jochem et al., 2012; Anand et al., 2009; Jager et al., 2004; Bessant \& Caffyn, 1997).

As iniciativas de cooperação entre empresas, clientes e fornecedoras favorecem a melhor compreensão dos problemas de processos por parte dos indivíduos (Irani et al., 2004; Bessant et al., 2001).
O questionário semiestruturado passou por um processo de teste-piloto antes de sua aplicação efetiva nos casos pesquisados. O teste-piloto compreendeu essencialmente o refinamento do texto das questões das partes $\mathrm{B}$ e $\mathrm{C}$ do questionário, visando a melhor compreensão por parte dos entrevistados. Para tanto, o questionário foi submetido à avaliação de três professores pesquisadores da área de gestão da qualidade. Das dezoito questões que compunham inicialmente o questionário, duas foram modificadas quanto ao texto e outra foi extraída, sendo o conteúdo desta última incorporado a outra questão.

\subsection{Análise de dados}

Cada caso gerou um relatório individual de pesquisa, dos quais foram analisados os dois principais conjuntos de informações coletados: as características dos programas de melhoria contínua e as competências habilitadoras desses programas. Desta forma, a 
primeira parte da análise dos casos individuais tem como foco apresentar os métodos adotados pelas organizações para a prática da melhoria contínua. A segunda parte, relacionada às competências para melhoria contínua, tem como ênfase a análise das competências organizacionais, extraídas do referencial teórico (Tabela 3).

\section{Evidências empíricas}

Nesta seção, serão apresentados os resultados dos quatro estudos de caso realizados nas empresas do setor automobilístico e de bens de capital sob encomenda. Primeiramente, são apresentados os casos A e B, referentes às empresas do setor automobilístico e, em seguida, os casos $\mathrm{C}$ e $\mathrm{D}$, referentes às empresas do setor de bens de capital. Posteriormente, é realizada uma análise dos casos intersetoriais, apresentando as diferenças quanto ao desenvolvimento das competências relacionadas à melhoria contínua de ambos os setores pesquisados.

\subsection{Empresa A}

\subsubsection{Características dos programas de melhoria}

A empresa apresenta um conjunto de programas de melhoria detalhados a seguir.

Programa "Fique de Olho na Qualidade": visa conscientizar todos os funcionários quanto à contribuição de cada processo para a satisfação dos clientes, motivando a detecção de falhas, além de promover o entendimento da relação fornecedor e cliente interno e externo. Neste programa, todos os funcionários são envolvidos na solução de problemas e, uma vez identificado um desses pontos, os funcionários que atuam no processo promovem ações de melhoria juntamente com as áreas técnicas da empresa, cabendo ao setor de qualidade a medição do problema e os resultados que a melhoria promoveu.

"Farol do cliente": método empregado para o monitoramento sistemático da satisfação e acompanhamento de possíveis não conformidades nas unidades produtivas das empresas clientes. $\mathrm{O}$ principal agente desta abordagem é um funcionário residente no cliente que acompanha o processo no qual o produto da empresa é utilizado. Um papel importante que este residente realiza é a divulgação dentro de sua empresa da "voz do cliente" por meio de reuniões periódicas entre este funcionário e os membros internos da organização, promovendo interação empresa-cliente, além do desenvolvimento de melhorias.

Programa de Melhoria Oito Disciplinas (8D): método para resolução de problemas, estudando-os por meio de oito aspectos: (i) processo envolvido; (ii) definição do problema; (iii) ações imediatas para conter o problema; (iv) origem do problema (a causa raiz); (v) planejamento e seleção de ações corretivas permanentes; (vi) implementação das ações corretivas e verificação dos resultados; (vii) identificação de problemas remanescentes adjascentes ao problema resolvido; (viii) retenção e distribuição do conhecimento adquirido. Assim, além de efetuar a resolução de problemas do processo, este programa realiza o armazenamento das melhores práticas e a divulgação dos sucessos e fracassos, habilitando a aprendizagem individual e organizacional por meio do envolvimento dos funcionários e disseminação do conhecimento.

Programa de melhoria kaizen: realizado sistematicamente, este programa é focado em projetos especiais de melhoria. A gerência de produção define uma meta de melhoria a ser alcançada para um determinado processo e estabelece um grupo multidisciplinar, formado por 4 a 5 funcionários, bem como o prazo para realização do projeto, que normalmente varia entre 7 e 21 dias, e os recursos disponíveis para a execução (orçamento, equipamentos e materiais). A empresa apresenta uma meta de realização de 30 projetos kaizen por ano, que é atrelada ao programa de participação de lucros e resultados da empresa, e, além disso, a equipe de projeto kaizen é recompensada com um valor pago em função dos resultados obtidos pela melhoria. Desta forma, este programa promove a integração dos funcionários de diferentes áreas da empresa, fomentando o debate, a troca de informações, o senso crítico, a aplicação de ferramentas da qualidade para a identificação e análise do problema, além da aprendizagem em direção a um objetivo comum.

Todos os métodos expostos que apoiam a prática da melhoria contínua são centralizados no setor de qualidade, quanto à gestão, coordenação, análise e formação de base de dados. Deste modo, o gerente de qualidade é, ao mesmo tempo, o gerente de melhoria contínua, que responde pelo andamento de todas estas iniciativas.

\subsubsection{Análise das competências organizacionais}

Por meio dos métodos utilizados para a prática da melhoria contínua, é possível perceber que essa organização conscientiza e fomenta ações de melhoria por parte de todos os indivíduos, principalmente por meio do programa "Fique de Olho na Qualidade".

Os funcionários são considerados um diferencial para o êxito da empresa e participam ativamente das atividades que visam a mudanças nos processos, tanto no planejamento quanto na execução. Os programas de melhoria apresentam diversos canais para a integração dos funcionários de diferentes níveis hierárquicos, favorecendo o envolvimento e utilização de ferramentas para resolução de problemas pelos indivíduos. 
A participação constante dos funcionários em identificação de problemas, sugestão e ações para melhoria eliminam, quase que totalmente, possíveis focos de resistência, pois o envolvimento dos indivíduos nestas atividades é a principal ação que uma empresa pode desenvolver a fim de eliminar focos de resistivos.

O programa "Farol do cliente" age como um instrumento de disseminação do foco do cliente, possibilita que os funcionários aumentem a compreensão quanto à importância de seus processos, bem como o foco estratégico da empresa.

Para a formação de funcionários capacitados a desenvolverem iniciativas de melhoria, a empresa apresenta um modelo de desenvolvimento de competências denominado $360^{\circ}$ :

- Avaliação dos funcionários pelo seu superior imediato, por um representante de seu cliente imediato (interno ou externo) e por um funcionário que trabalhe em conjunto;

- Avaliação das informações obtidas na etapa anterior pelo pessoal de Recursos Humanos;

- Definição de um programa de desenvolvimento pessoal, composto por uma série de iniciativas como treinamento, rotação de cargo e visita a clientes ou fornecedores.

Esta postura da empresa em estimular e desenvolver as competências dos funcionários, mantendo-os atualizados quanto aos conhecimentos e habilidades que a organização carece, torna-os aptos a praticarem melhorias constantes, além de constituir um ponto de motivação.

A integração dos funcionários por meio de reuniões, debates e os muitos programas de melhoria estimulam a aprendizagem organizacional. A empresa apresenta ainda um banco de dados, administrado pelo setor da qualidade, que disponibiliza para todos os funcionários as melhores práticas. Estas ações são relatadas pelos próprios funcionários operacionais em suas atividades de rotina em formulários específicos. A Tabela 4 resume as principais competências organizacionais, relacionadas à melhoria contínua, praticadas pela empresa A.

\subsection{Empresa B}

\subsubsection{Características dos programas de melhoria}

A implementação de programas voltados para a melhoria contínua ocorreu juntamente com o processo de revisão do sistema de gestão da qualidade a fim de atender aos novos requisitos da norma NBR ISO 9001:2000, (ABNT, 2000) no ano de 2002.
Depois deste processo, a organização se mobilizou a fim de coordenar e gerenciar as ações de melhoria e, para isso, criou um departamento denominado PSE (Production System Efficiency). Este departamento da organização pode ser considerado um setor de atividades kaizen permanente, possuindo as seguintes características:

- Presença de um gerente para o departamento: gerente de melhoria contínua;

- Departamento bastante enxuto, formando por cinco funcionários: o gerente de melhoria contínua, um engenheiro industrial, uma secretária e dois estagiários técnicos;

- O gerente do PSE possui a autonomia para formar equipes de melhoria de acordo com a necessidade que tais atividades envolvam;

- As ações de melhoria do PSE normalmente envolvem pequeno aporte financeiro e funcionários de diferentes funções;

- O PSE atua também com um ‘armazenador' do conhecimento adquirido, criando relatórios ao fim de cada projeto de melhoria desenvolvido;

- Depois do término das ações de melhoria, o grupo é destituído.

Uma forma de organização da produção que emergiu juntamente com o PSE foram os Grupos Autônomos de Produção (GAPs). Por meio de sua instituição, a função produção foi dividida em duas áreas principais: conformação do escapamento e soldagem do escapamento.

A implantação dos GAPs envolveu a eliminação das chefias intermediárias, denominadas nesta empresa de líderes de turno e supervisores de produção, visando dar aos funcionários maior responsabilidade pelo cumprimento das metas e pelo próprio desenvolvimento do trabalho. O processo de transição do modelo de produção tradicional com chefias imediatas para um modelo com maior autonomia foi bastante lento e árduo, pois envolveu um reposicionamento funcional dos cargos dos funcionários e um amplo processo de capacitação. Antes de sua completa introdução, os funcionários dos GAPs passaram por treinamentos técnicos específicos, isto é, voltados aos processos produtivos, envolvendo competências nas áreas de mecânica geral, pneumática, usinagem, eletricidade e soldagem; competências de apoio ao processo produtivo, abrangendo manutenção, controle da qualidade e planejamento da produção; e também competências humanas e gerenciais, no que diz respeito à comunicação, trabalho em equipe e liderança. Esta forma de organização da produção permite ao gerente do PSE contar com funcionários 
Tabela 4. Competências avaliadas na empresa A.

\section{Competências que sustentam a prática da melhoria contínua}

Entendimento das metas organizacionais

Sistema de gestão estruturado para a melhoria contínua

Apoio e envolvimento gerencial

Envolvimento dos funcionários

Melhoria desenvolvida em grupo

Autonomia para a prática da melhoria

Desenvolvimento de competências

Cultura voltada para melhoria contínua

Aprendizagem

Compartilhamento do conhecimento

Interação intraorganizacional

\section{Competências apresentadas pela empresa $\mathrm{A}$}

As metas da empresa para a qualidade são divulgadas por meio da divulgação do foco do cliente pelo método "Farol do Cliente".

As atividades de melhoria contínua são coordenadas pelo gerente de qualidade.

A gerência direciona os objetivos das iniciativas de melhoria e provê recursos para tanto conforme ocorre nos projetos Kaizen.

Os funcionários se envolvem sistematicamente em processos de resolução de problemas e são estimulados principalmente por meio de estímulos financeiros como participação e lucros e bônus.

Grande parte dos programas de melhoria apresentados pela empresa são promovidos em grupos, como os projetos Kaizen e 8 disciplinas.

Os funcionários possuem autonomia para a resolução de pequenos problemas operacionais, entretanto, as melhorias que exigem maior dispêndio de recursos dependem da autorização da gerência.

A empresa realiza uma avaliação frequente das competências dos funcionários (método $360^{\circ}$ ) e, a partir desta, é elaborado um programa de treinamento aos funcionários.

A organização desenvolveu ao longo dos anos uma cultura voltada à resolução de problemas dos processos por meio de reuniões sistemáticas entre gestores e funcionários, estímulos motivacionais baseados em recompensas financeiras, treinamento e possibilidade de ascensão e estímulo à participação constante nos programas de melhoria presentes na empresa.

Problemas e melhorias são discutidos entre os grupos durante a execução de um projeto de melhoria como o Kaizen ou na resolução de problemas por meio do método $8 \mathrm{D}$. Os resultados das melhorias são anunciados à organização, porém as especificidades se restringem a um pequeno grupo.

Em relação ao conhecimento tácito, o conhecimento é disseminado por meio da interação dos funcionários em atividades de melhoria. $\mathrm{O}$ conhecimento também é explicitado e distribuído por meio do cadastramento das melhores práticas. No momento em que um grupo de funcionários se reúne para a resolução de um problema, todos os indivíduos do grupo têm acesso a este banco de dados.

A interação dos funcionários com os clientes ocorre por meio do funcionário residente, oriundo do programa "Farol do cliente". Este funcionário tem o contato direto com o cliente e dissemina suas necessidades aos demais funcionários por meio de reuniões sistemáticas. operacionais com maior conhecimento em relação às oportunidades de melhoria.

Um programa de melhoria promovido internamente nos GAPs é o QRQC (Quick Response Quality Control ou Controle de Qualidade de Resposta Rápida) que promove ações de melhoria e correção dos processos no momento da identificação da oportunidade ou do desvio, abordando os seguintes fatores: objeto de melhoria, problema identificado, causa do problema, ação a ser tomada, responsável pela ação e prazo para conclusão da melhoria.

O PSE também implantou o programa CLIC (Colaborador Livre para Inovar e Criar), que visa estimular a participação e o envolvimento dos funcionários operacionais com sugestões que promovam a melhoria, alimentando o PSE de atividades que este julgue de relevante importância para a empresa.
A empresa também possui um funcionário residente nos clientes, ou seja, a "voz do cliente", que atua numa postura mais reativa quanto à prática da melhoria, agindo na solução de problemas identificados nos processos produtivos dos clientes. Este funcionário não é explorado no sentido de interagir com funcionários internos à empresa a fim de explorar eventuais oportunidades em relação aos clientes.

\subsubsection{Análise das características organizacionais}

O modelo para gerenciamento da melhoria, centralizando estas ações em um departamento, a liberdade cedida aos funcionários operacionais em alimentar este departamento de ideias e sugestões, além da constante rotação de funcionários nas ações 
de melhoria, promovendo um completo envolvimento dos indivíduos, capacita essa empresa a praticar a melhoria contínua.

A aliança dos GAPs com um departamento que gerencia as atividades de melhoria contínua desses grupos (PSE) foi bastante benéfica para a melhoria dos processos e para a extinção de focos de resistência a mudanças que sempre foi considerada uma grande barreira ao desenvolvimento da empresa.

A constante participação dos funcionários dos GAPs no PSE e os demais instrumentos de solução de problemas e melhoria de processos, utilizados por funcionários desde níveis gerenciais até operacionais, vêm tornando a empresa cada vez mais hábil em desenvolver seus programas de melhoria, além de criar um consenso da importância da qualidade para a competitividade empresarial.

A organização do trabalho produtivo por meio de GAPs auxilia a empresa a mapear e desenvolver as competências necessárias a cada indivíduo. O mapeamento das competências é realizado anualmente pelo gestor de produção e seu staff, que avalia todas as habilidades e conhecimentos necessários para que determinado indivíduo exerça com excelência sua função, levando em consideração três tipos de competências:

- Técnicas, que se referem ao conhecimento técnico exigido para o desenvolvimento de determinada função;

- Envolvendo as atividades de apoio à manufatura: manutenção, controle da qualidade e planejamento da produção;

- Gerenciais, que tratam da capacidade de liderança, organização e trabalho em equipe.

Neste mapeamento é identificado em qual nível se encontra atualmente determinada competência do funcionário, classificando-a em três distintos níveis, que variam de plenamente satisfatória a insatisfatória. A partir desta classificação é elaborado um plano de treinamento que o funcionário passará durante o ano.

Uma reunião diária denominada "Top Five", na qual se discutem os principais problemas de produção do dia anterior, envolvendo funcionários de diferentes níveis hierárquicos atuantes nos processos, constitui um instrumento que, além de solucionar problemas, promove a aprendizagem dos indivíduos por meio da interação e interpretação de determinada situação.

O QRQC também é uma ferramenta que estimula a aprendizagem individual em que fatos e problemas são discutidos e, deste modo, a informação pode ser interpretada e integrada ao grupo participante. O QRQC também representa um mecanismo de resgate das lições aprendidas por meio das seguintes ações:
- Divulgação de informações aos grupos de operadores dos GAPs;

- Atualização dos documentos envolvidos na melhoria;

- Atualização do plano de controle de fabricação;

- Atualização de esquemas e desenhos;

- Divulgação de relatório acerca dos resultados obtidos para todos os funcionários.

A manufatura organizada por grupos semiautônomos exige dos funcionários maior nível de comprometimento com as metas da organização, aumentando o envolvimento e interesse por atividades de melhoria e, consequentemente, o potencial de gerar um ambiente de aprendizagem. Além disso, o PSE atua como um mecanismo de resgate das lições aprendidas nas iniciativas de melhoria. Desta forma, o conhecimento adquirido é armazenado em relatórios e disseminado aos participantes de novas iniciativas de melhoria. A Tabela 5 resume as principais competências desenvolvidas pela empresa que sustentam a melhoria contínua.

\subsection{Empresa C}

\subsubsection{Características dos programas de melhoria}

Os esforços por melhoria da qualidade são concentrados em dois sentidos O primeiro trata da resolução de problemas identificados no processo, denominado de melhoria não planejada. Quando um operador do processo produtivo identifica um problema, este comunica ao supervisor de produção que discute com a equipe de engenharia o processo de resolução. O envolvimento dos funcionários de chão de fábrica é restrito à execução do plano de melhoria desenvolvido pelo supervisor e grupo de engenharia. O segundo refere-se às melhorias planejadas, isto é, quando o grupo de engenharia avalia que o processo necessita de um redesenho, organiza-se um plano para desenvolver uma mudança no processo que, geralmente, é de grande porte.

As maiores ações de melhoria dos processos promovem grandes mudanças em relação à sua concepção inicial, sendo despendidos grandes montantes de recursos e alterando-se bruscamente a rotina dos indivíduos envolvidos.

O baixo envolvimento dos funcionários operacionais é um fator diretamente ligado à característica da melhoria praticada na empresa. Os maiores esforços pela busca de melhores resultados são realizados por funcionários com maior grau de instrução, geralmente com nível superior completo, e coordenados pelos diretores e/ou gerentes de seus respectivos setores. 
Tabela 5. Competências avaliadas na empresa B.

\section{Competências que sustentam a prática da melhoria contínua}

Entendimento das metas organizacionais

Sistema de gestão estruturado para a melhoria contínua

Apoio e envolvimento gerencial

Envolvimento dos funcionários

Melhoria desenvolvida em grupo

Autonomia para a prática da melhoria

Desenvolvimento de competências

Cultura voltada para melhoria contínua

Aprendizagem

Compartilhamento do conhecimento

Interação intraorganizacional

\section{Competências apresentadas pela empresa $B$}

O princípio de produção semiautônoma tornou os funcionários mais envolvidos e comprometidos com as metas da organização.

As atividades de melhoria contínua são coordenadas e centralizadas em um departamento denominado PSE.

A eliminação das chefias intermediárias exigiu da gerência de produção um maior envolvimento em relação aos grupos de trabalho. O gerente de melhoria contínua também atua junto às equipes para o cumprimento dos objetivos de melhoria.

Os funcionários dos GAPs se envolvem com ações de melhoria sob coordenação e apoio do PSE. A autonomia cedida aos GAPs torna os funcionários conscientes da importância do cumprimento das metas de melhoria.

As iniciativas de melhoria são desenvolvidas em grupos formados e coordenados pelo PSE.

Os funcionários dos GAPs possuem autonomia para propor ideias e participar das iniciativas de melhoria. Contudo, todas as iniciativas de melhoria devem ser gerenciadas e organizadas pelo PSE.

As competências técnicas, de apoio e gerenciais são avaliadas e desenvolvidas a partir das necessidades que cada GAP apresente.

O PSE, além de gerenciar as ações de melhoria, possui o papel de desenvolver um contexto organizacional voltado à melhoria. A organização do trabalho via GAP também promove o maior envolvimento e interesse por parte dos funcionários.

A aprendizagem dos funcionários ocorre por conta de dois fatores. O primeiro refere-se às competências exigidas pelos GAPs, capacitando os funcionários de forma a tornaram-se polivantes. A segunda diz respeito ao envolvimento dos funcionários em atividades de melhoria em grupos multidisciplinares organizadas pelo PSE.

O conhecimento tácito é compartilhado por meio das interações que os programas de melhoria exigem; e o conhecimento explícito é armazenado no PSE e distribuído aos grupos de melhoria, quando esses são formados.

A interação dos funcionários com empresas externas se dá exclusivamente via o funcionário residente no cliente. Este funcionário acompanha sistematicamente o produto da empresa no cliente e elabora relatórios mensais acerca do comportamento do produto para os gerentes.
Estas melhorias, em sua maioria de ruptura, contribuem efetivamente para o aumento de competitividade da empresa e para a maior satisfação dos clientes. Contudo, não é utilizada a abordagem de melhoria contínua considerada pelo kaizen, isto é, existe pequena participação dos funcionários, grandes montantes de investimento e profundas modificações na estrutura do processo.

\subsubsection{Análise das características organizacionais}

A abordagem utilizada por essa organização para melhoria de desempenho dos processos e solução de problemas não favorece a prática da melhoria contínua, não havendo um estímulo para os funcionários de todos os níveis a se envolverem com as atividades que visem à melhoria. Pode-se classificar a estratégia para a prática de melhoria como "top down", isto é, um grupo de nível hierárquico mais elevado planeja ações de melhoria e desdobra para os demais funcionários.

Essa estratégia de melhoria é considerada apropriada para aumentar a competitividade tecnológica, contudo a ausência de uma estratégia voltada a incremento contínuo do desempenho do processo, numa perspectiva "bottom up", que promova a maior participação dos funcionários, pode reduzir a eficiência dos processos. $\mathrm{O}$ que se pode observar quanto à participação dos indivíduos é que os funcionários de chão de fábrica apenas reagem às propostas efetuadas por gestores e pelas equipes de melhoria. 
A resistência à mudança, que poderia ser constatada devido à estratégia de melhoria adotada, é pouco manifestada. Os grupos de melhoria, antes de implementar uma mudança, procuram realizar treinamentos e debates com os funcionários envolvidos com o processo modificado, conscientizando-os quanto à necessidade da melhoria.

Quanto ao desenvolvimento de competências, a empresa, anualmente, mapeia e avalia as competências de cada indivíduo, sendo tal atividade realizada pelos supervisores dos funcionários por meio do convívio e da observação na prática do desenvolvimento das atividades. Depois desta análise, os gestores dos processos contrapõem as competências essenciais planejadas para seus processos com as competências manifestadas pelos indivíduos, oferecendo treinamentos que complementem suas formações. A maior parte do conhecimento adquirido nestas seções de treinamento visa melhorar o desempenho das atividades de rotina, quando se analisam os funcionários de níveis operacionais.

O ambiente rústico que a indústria de caldeiraria possui, exigindo grandes esforços físicos de seus trabalhadores, não estimula os funcionários de chão de fábrica a estudarem e se envolverem de uma forma que promova melhorias. E, os gestores, cientes desta situação, acabam não integrando esses funcionários no planejamento das atividades de melhoria.

Embora a organização envolva grande parte de seus funcionários em seções de treinamentos, a restrição quanto à participação no planejamento e desenvolvimento de ações que visem à melhoria torna a aprendizagem individual bastante reduzida.

O resgate dos sucessos e fracassos alcançados pelas melhorias implantadas é promovido por meio de relatórios e um sistema de informação eletrônico que divulga os resultados destas ações, todavia este instrumento de disseminação da aprendizagem é restrito a apenas um pequeno grupo da organização, composto de diretores, gerentes, supervisores e engenheiros.

Pode-se perceber, neste ambiente produtivo, a forte atuação de grupos técnicos no desenvolvimento de melhoria, contudo sem a participação do pessoal de chão de fábrica, sendo que a aprendizagem individual ocorre mais consistentemente no primeiro grupo, e de forma limitada no segundo, limitando a aprendizagem organizacional. A Tabela 6 resume as principais competências desenvolvidas pela empresa C para a prática da melhoria contínua.

\subsection{Empresa D}

\subsubsection{Características dos programas de melhoria}

O processo de melhoria contínua é restrito a um grupo de funcionários ligado aos níveis hierárquicos mais elevados, composto de engenheiros, técnicos e supervisores da área de produção, que planejam e implementam mudanças visando a um "salto" de desempenho.

As ações de melhoria são impostas pela alta gerência, direcionadas estrategicamente, e desdobradas aos departamentos funcionais pelo Strategic Meeting, que ocorre anualmente visando ao alinhamento dos objetivos e metas organizacionais nas divisões departamentais. Mensalmente, a empresa realiza reuniões com o objetivo de direcionar os esforços de melhoria dentro da unidade com a participação dos gestores dos processos e dos grupos responsáveis pelas mudanças. Contudo o envolvimento de funcionários de nível operacional nas atividades de melhoria é bastante reduzido, limitando-se a sugerir pequenas modificações após a implementação de melhorias pelo grupo especializado.

As iniciativas de melhoria são classificadas da seguinte forma: melhoria emergencial e redesenho do processo. A primeira é voltada à resolução de problemas identificados que impactam a produtividade do processo e a qualidade do produto. Esses problemas, em sua maioria, são apontados pelos operadores ou supervisores de produção, que encaminham a necessidade de intervenção à engenharia, num caráter reativo, que desenvolvem a resolução de problemas seguindo os princípios do MASP (Método de Análise e Solução de Problemas). O redesenho do processo é originado das metas desdobradas do Strategic Meeting. Todo início de ano, após o desdobramento do Strategic Meeting, o grupo responsável por ações de melhoria (engenheiros, técnicos, supervisores e coordenadores de produção) planeja estas iniciativas de melhoria com o cronograma se estendendo durante todo o ano corrente. Normalmente, estas iniciativas de redesenho do processo são tratadas como projetos seis sigma, e o processo de planejamento, execução e controle das ações seguem o ciclo DMAIC.

Em relação à gestão, as iniciativas de melhoria emergencial e redesenho dos processos são centralizadas no departamento de engenharia industrial. Este departamento é responsável pelo planejamento, execução e controle das ações de melhoria, e também pela geração e armazenamento dos relatórios e procedimentos adotados em torno destas iniciativas.

\subsubsection{Análise das características organizacionais}

As características dos programas de melhoria adotados por esta organização não propiciam a difusão de tal prática para todos os funcionários atuantes nos processos, restringindo-se a pequenos grupos ligados à direção. Assim, a busca por melhoria não está presente no comportamento de todos os indivíduos da organização, sendo um foco exclusivo a gestores e grupos especializados. 
Tabela 6. Competências avaliadas na empresa C.

\begin{tabular}{ll}
\hline $\begin{array}{c}\text { Competências que sustentam a } \\
\text { prática da melhoria contínua }\end{array}$ & \multicolumn{1}{c}{ Competências apresentadas pela empresa C } \\
\hline $\begin{array}{l}\text { Entendimento das metas } \\
\text { organizacionais }\end{array}$ & $\begin{array}{l}\text { A explicitação do direcionamento estratégico é restrita apenas aos grupos de } \\
\text { níveis hierárquicos superiores. }\end{array}$ \\
$\begin{array}{l}\text { Sistema de gestão estruturado para } \\
\text { a melhoria contínua }\end{array}$ & $\begin{array}{l}\text { As atividades de melhoria são gerenciadas como ações que visam mudanças de } \\
\text { ruptura do processo. }\end{array}$ \\
Apoio e envolvimento gerencial & $\begin{array}{l}\text { Os gestores se envolvem com melhorias de grande porte. As iniciativas de } \\
\text { resolução de problemas são restritas aos supervisores de produção e grupo de } \\
\text { engenharia. }\end{array}$
\end{tabular}

Envolvimento dos funcionários

As atividades de melhoria são restritas a um pequeno grupo de nível hierárquico intermediário ou superior. Os níveis inferiores contribuem apenas com a execução de partes dos planos de melhoria propostos.

Melhoria desenvolvida em grupo

Autonomia para a prática da melhoria

As melhorias são desenvolvidas em grupos técnicos especializados.

Os projetos de melhoria são bastante delimitados pela alta gerência, cabendo aos grupos especializados seu planejamento e execução.

Desenvolvimento de competências O supervisor de cada funcionário avalia por meio do convívio diário as competências de seus funcionários e, a partir desta avaliação, a empresa organiza treinamentos.

Cultura voltada para melhoria contínua

A cultura vigente é direcionada à resolução de problemas e a iniciativas de ruptura.

Aprendizagem

Os grupos técnicos especializados e supervisores aprendem por meio de experimentação ao planejar e executar uma resolução de um problema e, também, por meio do planejamento e execução de projetos de grande porte de melhoria. Dessa forma, a aprendizagem é restrita aos níveis intermediários e superiores.

Compartilhamento do conhecimento

O conhecimento é retido de forma tácita aos funcionários participantes dos projetos de melhoria. A empresa também apresenta um sistema de informação que visa armazenar as lições aprendidas e divulgá-las aos funcionários técnicos especializados e de nível gerencial.

Interação intraorganizacional Os grupos de engenharia e supervisão interagem com empresas fornecedoras e clientes.

A autonomia dos funcionários de níveis hierárquicos inferiores da organização para a realização de ações que visem à melhoria ou resolução de problemas dos processos é pequena. Além disto, os funcionários de nível operacional não são envolvidos no planejamento e execução das ações de melhoria emergencial, que visam à resolução de problemas, nem nas melhorias de nível maior, denominadas de redesenho de processo. Desse modo, existe pouco empenho por parte da direção da empresa em disseminar a prática da melhoria à totalidade dos funcionários.

A resistência à mudança constitui uma das maiores dificuldades em implementar ações de redesenho de processo. Esta resistência pode ser explicada pelo fato de os funcionários operacionais não participarem do planejamento e implementação das ações de melhoria, que, na maioria das vezes, são ações de grande porte, gerando certa negligência destes funcionários quanto à adaptação aos novos processos.

Os funcionários de média gerência, engenharia e técnicos são estimulados a realizar visitas a fornecedores, clientes e outras unidades da própria empresa no Brasil e no exterior, além de haver um incentivo para a participação em treinamento conforme as necessidades específicas de cada cargo, porém não existe um método estruturado de desenvolvimento de competências.

Os instrumentos de aprendizagem e disseminação do conhecimento que esta organização apresenta são restritos aos funcionários de níveis hierárquicos mais altos e daqueles envolvidos nos projetos de melhoria. Para esses indivíduos, existe uma série de atividades que possibilitam a aprendizagem:

- Uma forte interação com funcionários de unidades da empresa no exterior;

- Sistema de comunicação virtual que liga os funcionários de todas as unidades;

- Treinamentos ocorridos com maior frequência;

- Participação no Staff Meeting, que consiste em encontros de área e reuniões setoriais, nas 
quais as experiências são compartilhadas entre os indivíduos;

- Acesso à base de dados corporativa, que contém as melhores práticas da organização.

Assim, é possível concluir que a aprendizagem individual ocorre apenas em um pequeno grupo e a organização não aproveita todo o potencial de conhecimento e habilidades de seus indivíduos, reduzindo o potencial de aprendizagem e de ações de melhoria. A Tabela 7 resume as principais competências desenvolvidas pela empresa D para a prática da melhoria contínua.

\subsection{Análise comparativa das competências que sustentam a melhoria contínua nas empresas pesquisadas dos setores automobilístico e de bens de capital}

A prática da melhoria contínua, baseando-se em sua definição de pequenos passos, alta frequência e elevada participação dos funcionários (Bessant \& Caffyn, 1997), é mais intensamente desenvolvida nas empresas do automobilístico pesquisadas, em detrimento às empresas do setor de bens de capital. As próprias características relativas aos sistemas de produção, do trabalho e dos indivíduos que compõem as organizações destes dois setores explicam um pouco esta diferença de condução.

Tabela 7. Competências avaliadas na empresa D.

\section{Competências que sustentam a prática da melhoria contínua \\ Competências apresentadas pela empresa D}

Entendimento das metas organizacionais As metas organizacionais são descritas apenas para grupos específicos da organização.

Sistema de gestão estruturado para a melhoria contínua

Apoio e envolvimento gerencial

Envolvimento dos funcionários

Melhoria desenvolvida em grupo Autonomia para a prática da melhoria

Desenvolvimento de competências

Cultura voltada para melhoria contínua Aprendizagem

Compartilhamento do conhecimento

Interação intraorganizacional
As ações de melhoria são centralizadas no departamento de Engenharia Industrial.

Os gestores de nível hierárquico superior se envolvem, essencialmente, nas ações de redesenho de processo, desde a formulação das metas de melhoria pelo Strategic Meeting, até o acompanhamento das ações. A média gerência apresenta envolvimento mais amplo, desde ações de redesenho de processo até resolução de problemas emergenciais.

As atividades de melhoria são restritas a um pequeno grupo de nível hierárquico intermediário ou superior. Os níveis inferiores contribuem apenas com o refinamento das melhorias introduzidas nos processos.

As melhorias são desenvolvidas por grupos técnicos especializados

Os grupos especializados possuem bastante autonomia para planejar e executar as ações de melhoria. As metas que direcionam estas iniciativas, por sua vez, são formuladas pela alta gerência por meio do Strategic Meeting

Embora estimule a participação em treinamentos específicos de cada área de atuação de seus funcionários, a organização não apresenta um método estruturado para desenvolvimento de competências.

A cultura vigente é direcionada à resolução de problemas e a iniciativas de ruptura.

Os grupos técnicos especializados e supervisores aprendem por meio de experimentação ao planejar e executar uma resolução de um problema e, também, por meio do planejamento e execução de projetos de grande porte de melhoria. Dessa forma, a aprendizagem é restrita aos níveis intermediários e superiores.

Além do compartilhamento de conhecimento tácito via interação pessoal, esta empresa apresenta diversos mecanismos para retenção e compartilhamento de conhecimento e experiências como o registro das ações empreendidas, sistema virtual de comunicação entre unidades e reuniões sistemáticas para o planejamento e acompanhamento das melhorias. Entretanto, estes instrumentos são restritos a grupos específicos.

Os grupos de engenharia, técnicos e média gerência interagem com empresas fornecedoras, clientes e outras unidades da própria organização. 
Enquanto as empresas pesquisadas do setor automobilístico apresentam processos mais estáveis e repetitivos, que favorecem a experimentação e aprendizagem contínua, as empresas do setor de bens de capital apresentam processos bem menos repetitivos, que respondem a encomendas específicas dos clientes, e não favorecem a aprendizagem contínua. O próprio conteúdo do trabalho e característica da mão de obra são fatores que interferem na prática da melhoria contínua.

As duas empresas do setor automobilístico pesquisadas estruturaram programas para a prática da melhoria contínua, sendo gerenciados pelo departamento da qualidade, como no caso A; e por um departamento específico para este fim, denominado de PSE (Production System Efficiency), no caso da empresa B. Em geral, as duas empresas possuem similaridades quanto à condução de seus programas de melhoria contínua, apresentando um alto nível de participação dos funcionários de diferentes níveis hierárquicos e, também, uma liderança ativa por parte dos gestores de ambas as organizações. A gestão centralizada dos programas de melhoria, que ocorrem em especial, na empresa B, favorece o planejamento e a mobilização de recursos humanos e financeiros necessários para a condução das ações. Além disto, este formato de gestão favorece a divulgação e disseminação dos valores da melhoria contínua para os demais departamentos das organizações, facilita o direcionamento estratégico das atividades, a mensuração dos resultados conquistados e a cobrança dos responsáveis.

Em contrapartida, as empresas pesquisadas do setor de bens de capital não apresentam sistemas de gestão centralizados para a melhoria contínua. As duas empresas pesquisadas apresentam grupos especializados em melhorias dos processos que são responsáveis exclusivamente em tratar esses programas. Assim, as atividades de melhoria são restritas aos grupos hierárquicos mais elevados da organização, contando com a participação de diretores, gerentes, supervisores e dos grupos especializados em melhoria, sendo esse último composto de engenheiros e técnicos que estudam e propõem ações para melhoria dos processos.

Nas duas empresas de bens de capital, os funcionários operacionais apenas reagem às ações de melhoria introduzidas pelos grupos especializados. Esta estratégia de melhoria é de característica "top down", ou seja, diretores e gerentes planejam as ações de melhoria e desdobram estas aos grupos operacionais, trazendo benefícios quanto ao aumento de competitividade tecnológica, porém, no longo e médio-prazo, resulta em menor produtividade e motivação dos funcionários com o trabalho. Assim, a participação do grupo operacional nos programas de melhoria é restrita ao refinamento e adequações das ações introduzidas por meio da atividade diária nos processos a fim de tornar as melhorias operacionalizáveis.
Quanto ao porte das atividades de melhoria, as empresas A e B do setor automobilístico apresentam iniciativas de pequeno e também de grande porte. Esta complementaridade entre atividades de melhoria de pequeno e grande porte é essencial para o aumento da competitividade, permitindo a organização atuar simultaneamente nos níveis de controle, reativo e proativo de melhoria. Assim, as melhorias pequenas são adotadas nos processos continuamente, porém, quando estes não atendem mais às demandas do mercado, iniciativas de grande porte são introduzidas.

Já as empresas $\mathrm{C}$ e $\mathrm{D}$ de bens de capital apresentam atividades de melhoria, em sua maioria de grande porte, caracterizando-se como uma reengenharia dos processos e acarretando grandes montantes de recursos para sua realização. Essas características de melhoria que as duas empresas expõem, grandes mudanças, alto montante de investimento e baixo envolvimento, contrapõem-se com a definição de melhoria contínua exposta por diversos autores como Bessant et al. (1994, 2001) e Imai (1997), que definem a melhoria contínua como atividades de alta frequência, pequenos passos e alto envolvimento.

Desta forma, é possível afirmar que as duas empresas pesquisadas do setor automobilístico apresentam cultura organizacional voltada à aprendizagem, percebida por meio de elementos como foco estratégico, envolvimento de indivíduos de diferentes níveis hierárquicos em atividades de melhoria, fluxo de informação e conhecimento horizontal e vertical na organização, indivíduos motivados a buscarem melhorias em seus processos, processos de experimentação e tentativa e erro são apoiados pelas respectivas direções, desenvolvimento de melhoria em grupos e compartilhamento de conhecimento e melhores práticas.

Em relação às empresas pesquisadas do setor de bens de capital, existe uma clara distinção entre aqueles que planejam e melhoram os processos e um segundo grupo responsável pela operação e refinamento das ações de melhoria introduzidas aos processos.

Em relação ao desenvolvimento de competência, as duas empresas do setor automobilístico apresentam processos estruturados e formalizados para este fim. As empresas orientam o desenvolvimento dos funcionários a partir do desdobramento das competências essenciais da organização em competências requisitadas pelos diferentes processos organizacionais. Os indivíduos, por sua vez, são avaliados por seus respectivos supervisores e gestores em torno destas competências desdobradas. Por fim, os programas de treinamento são orientados pelos resultados das avaliações realizadas. Desta forma, percebe-se que as organizações se preocupam em desenvolver indivíduos com competências suficientes a exercerem suas funções e desenvolverem iniciativas de melhoria. 
As empresas do setor de bens de capital também apresentam mecanismos para o desenvolvimento de competências. De forma similar às empresas A e B, as duas empresas pesquisadas do setor de bens de capital realizam avaliações de seus funcionários por meio dos supervisores e gestores diretos, e, a partir destas avaliações, são propostos treinamentos. A principal diferença entre o formato do desenvolvimento de competências apresentado pelas empresas do setor automobilístico e de bens de capital reside no fato de que as empresas A e B preocupam-se em alinhar as competências dos funcionários às suas competências essenciais, enquanto nas empresas $\mathrm{C}$ e $\mathrm{D}$, as competências exigidas dos funcionários são apontadas pelo supervisor direto, em função das necessidades que seu departamento apresente.

Quanto à aprendizagem organizacional, este processo é alicerçado nas empresas do setor automobilístico pela organização de diversos projetos de melhoria de pequeno porte, conduzidos por funcionários de diferentes departamentos e níveis hierárquicos. As atividades de melhoria organizadas em grupos multidisciplinares e o estímulo ao processo de tentativa e erro favorecem a aprendizagem individual. A aprendizagem se institucionaliza em nível organizacional, no momento em que os projetos de melhoria são inseridos aos processos, isto é, as rotinas organizacionais são modificadas e os indivíduos passam a reconhecer novas formas de executar o trabalho.

Em relação às empresas do setor de bens de capital, a aprendizagem individual ocorre por meio do planejamento, condução e controle de projetos de melhoria de grande porte e, também, pela identificação e solução de problemas, realizados por grupos multidisciplinares. Entretanto, a aprendizagem é restrita a pequenos grupos especializados em melhoria e a funcionários de níveis hierárquicos mais elevados das empresas $\mathrm{C}$ e $\mathrm{D}$, restringindo o nível de aprendizagem de ambas as organizações.

Quanto à retenção e disseminação do conhecimento adquirido, as quatro empresas pesquisadas apresentam mecanismos voltados para este fim. As empresas A e $B$ centralizam o armazenamento das melhores práticas e relatórios das iniciativas de melhoria em setores específicos, de qualidade e PSE, respectivamente. As bases de conhecimento das duas empresas são disponibilizadas a todos os funcionários que atuam em grupos de melhoria.

As empresas $\mathrm{C}$ e D não apresentam um setor específico para o tratamento da melhoria. A retenção das melhores práticas e lições aprendidas é centralizada no setor de engenharia industrial e a divulgação é restrita aos grupos especializados em melhoria. Desta forma, percebe-se que a abrangência do compartilhamento do conhecimento é reduzida quando se comparam as empresas do setor de bens de capital às empresas do setor automobilístico.
A abordagem para a melhoria apresentada pelas empresas de ambos os setores pesquisados apoia suas ações em duas direções. A primeira trata da melhoria de ruptura, visando obter níveis inéditos de desempenho, sendo realizadas esporadicamente. Normalmente, estas ações estão alinhadas com a estratégia da empresa, e tem por objetivo atender a novas exigências do mercado. Embora nas empresas de ambos os setores pesquisados estes projetos sejam originados da alta gerência, muitas vezes, em decorrência de metas desdobradas do planejamento estratégico das organizações, conclui-se que as duas empresas do setor automobilístico desenvolvem estas ações com maior participação dos funcionários operacionais, quando comparadas às empresas do setor de bens de capital.

Iniciativas visando incremento de desempenho dos processos, resolução de problemas e a reação às exigências dos clientes consistem no segundo direcionamento das ações de melhoria. Este segundo grupo de ações, por sua vez, é mais intensamente desenvolvido nas empresas do setor automobilístico, que apresentam programas fomentadores destas iniciativas, envolvendo grande número de funcionários. Em contrapartida, as empresas do setor de bens de capital restringem estas ações a grupos técnicos especializados e supervisores, tratando-as como resoluções de problemas. Desta forma, pode-se considerar que as empresas do setor de bens de capital adotam uma postura mais reativa na prática de melhoria contínua, evidenciando um processo que autores como Teare \& Monk (2002) caracterizam como "apagar incêndios".

\section{Considerações finais}

A pesquisa de campo aponta que as empresas de ambos os setores se preocupam com o desenvolvimento de ações de melhoria em seus processos produtivos. Contudo, existem diferenças relevantes quanto à condução destas atividades quando se analisam as empresas dos dois setores.

No caso das empresas automobilísticas, verifica-se que as organizações pesquisadas possuem programas de melhoria que buscam o maior envolvimento dos funcionários tanto de nível operacional quanto gerencial, constituindo-se em um processo de aperfeiçoamento contínuo e resolução de problemas, associado a melhorias de ruptura que ocorrem de forma mais esporádicas. As melhorias incrementais são realizadas pelos funcionários de chão de fábrica com apoio de engenheiros, técnicos e gestores dos processos.

Em contraposição, as empresas do setor de bens de capital focalizam os esforços de melhoria em grupos especializados, geralmente relacionados aos níveis de supervisão, gerência e engenharia, trabalhando estas ações como projetos de melhoria de grande porte ou resoluções de problemas operacionais 
crônicos. A participação do nível operacional fica restrita a pequenas sugestões e ajustes depois das mudanças terem sido implantadas, fato que, em algumas ocasiões, acabam gerando resistência à mudança por parte deste grupo.

A aprendizagem organizacional torna-se impactada pelo envolvimento dos funcionários. Ambientes organizacionais que apresentam contextos sociais de interação e integração dos indivíduos alcançam maiores níveis de aprendizagem que, por sua vez, sustentam a prática da melhoria contínua (Jochem et al., 2012; Caffyn, 1999).

O resgate e a utilização do conhecimento gerado pelos indivíduos também afetam diretamente a prática da melhoria contínua. A distribuição do conhecimento é limitada nas empresas pesquisadas do setor de bens de capital, que o torna disponível apenas para o grupo gerencial, e é mais ampla entre as empresas pesquisadas do setor automobilístico, fato este que se explica pela pouca integração dos indivíduos do primeiro grupo. Contudo, as empresas dos dois setores apresentam mecanismos de resgate e armazenamento das lições aprendidas.

Assim, o artigo conclui que as empresas dos dois setores pesquisados atuam no desenvolvimento de competências e no resgate das lições aprendidas, todavia as ações de melhoria das empresas pesquisadas do setor de bens de capital apresentam portes maiores e o envolvimento de poucos funcionários, geralmente especialistas. As empresas do setor automobilístico, por sua vez, têm suas ações de melhoria caracterizadas por programas participativos, combinando estratégias "top down" e "bottom up" com a participação de grande número de funcionários, apoio da supervisão e gerência e organizada por um departamento específico.

Em relação às limitações da pesquisa, deve-se salientar a quantidade de casos incluídos. O número limitado de empresas pesquisadas em cada setor limita a identificação de tendências e condutas comuns ao setor automobilístico e de bens de capital. Outra limitação refere-se à coleta de dados qualitativos, que, por sua vez, inviabiliza a possibilidade de generalizações dentro dos setores estudados.

Quanto às pesquisas futuras, os autores deste artigo propõem a realização de um estudo quantitativo, envolvendo técnicas multivariadas de análise de dados para identificação do comportamento das onze variáveis mapeadas neste artigo, referentes às competências que sustentam a prática da melhoria contínua. A utilização da análise discriminante multivariada possibilitará a identificação das variáveis que realmente são estatisticamente diferentes entre os dois setores, bem como aquelas que melhor discriminam a prática da melhoria contínua entre as empresas automobilísticas e de bens de capital.

Outra sugestão de trabalho futuro refere-se a uma análise das competências mais importantes para a obtenção de resultados positivos por meio da prática da melhoria contínua, utilizando um modelo de regressão multivariado. Neste contexto, será necessário identificar as variáveis dependentes, relativas aos resultados das ações de melhoria, e as variáveis independentes, por sua vez, constituirão as onze competências mapeadas neste artigo.

\section{Agradecimentos}

Os autores agradecem à FAPESP, processo $n^{\circ}$ 2013/02872-5 e CNPQ, processo n ${ }^{\circ} 445205 / 2014-8$ $\mathrm{o}$ apoio financeiro concedido a esta pesquisa.

\section{Referências}

Ali, A. J., Islam, M. A., \& Howe, L. P. (2013). A study of sustainability of continuous improvement in the manufacturing industries in Malaysia: organizational self-assessment as a mediator. Management of Environmental Quality, 24(3), 408-426. http://dx.doi. org/10.1108/14777831311322695.

Anand, G., Ward, P. T., Tatikonda, M. V., \& Schilling, D. A. (2009). Dynamic capabilities through continuous improvement infrastructure. Journal of Operations Management, 27(6), 444-461. http://dx.doi.org/10.1016/j. jom.2009.02.002.

Associação Brasileira de Normas Técnicas - ABNT. (2000). NBR ISO 9001:2000: Sistema de gestão da qualidade: requisitos. Rio de Janeiro: ABNT.

Bateman, N. (2005). Sustainability: the elusive element of process improvement. International Journal of Operations \& Production Management, 25(3), 261276. http://dx.doi.org/10.1108/01443570510581862.

Bessant, J., \& Caffyn, S. (1997). High involvement innovation through continuous improvement. International Journal of Technology Management, 14(1), 7-28. http://dx.doi. org/10.1504/IJTM.1997.001705.

Bessant, J., Caffyn, S., \& Gallagher, M. (2001). An evolutionary model of continuous improvement behavior. Technovation, 21(2), 67-77. http://dx.doi.org/10.1016/ S0166-4972(00)00023-7.

Bessant, J., Caffyn, S., Gilbert, J., Harding, R., \& Webb, S. (1994). Rediscovering continuous improvement. Technovation, 14(1), 17-29. http://dx.doi.org/10.1016/01664972(94)90067-1.

Bhuiyan, N., \& Baghel, A. (2005). An overview of continuous improvement: from de past to the present. Management Decision, 43(5), 761-771. http://dx.doi. org/10.1108/00251740510597761.

Bryman, A. (1989). Research methods and organization studies. London: Unwin Hyman.

Caffyn, S. (1999). Development of a continuous improvement self- assessment tools. International Journal of Operations \& Production Management, 19(11), 1138-1153. http:// dx.doi.org/10.1108/01443579910291050. 
Choo, A. S., Linderman, K. W., \& Schroeder, R. G. (2007). Method and context perspectives on learning and knowledge creation in quality management. Journal of Operations Management, 25(4), 918-931. http:// dx.doi.org/10.1016/j.jom.2006.08.002.

Gonzalez, R. V. D., \& Martins, M. F. (2011). Melhoria contínua e aprendizagem organizacional: múltiplos casos em empresas do setor automobilístico. Revista Gestão \& Produção., 18(3), 473-486.

Gonzalez, R. V. D., \& Martins, M. F. (2007). Melhoria contínua no ambiente ISO 9001:2000: estudo de caso em duas empresas do setor automobilístico. Revista Produção, 17(3), 592-603.

Imai, M. (1997). Gembra Kaizen: a commonsense, low cost approach to management. New York: McGraw-Hill.

Irani, Z., Beskese, A., \& Love, P. E. D. (2004). Total quality management and corporate culture: constructs of organizational excellence. Technovation, 24(8), 643650. http://dx.doi.org/10.1016/S0166-4972(02)00128-1.

Jaca, C., Viles, E., Mateo, R., \& Santos, J. (2012). Components of sustainable improvement systems: theory and practice. The TQM Journal., 24(2), 142-154. http:// dx.doi.org/10.1108/17542731211215080.

Jager, B., Minnie, C., Jager, J., Welgemoed, M., Bessant, J., \& Francis, D. (2004). Enabling continuous improvement: a case study of implementation. Journal of Manufacturing Technology Management, 15(4), 315-324. http://dx.doi. org/10.1108/17410380410535017.

Jochem, R., Geers, D., \& Heinze, P. (2012). Maturity measurement of knowledge-intensive business process. The TQM Journal, 23(4), 377-387.
Jurburg, D., Viles, E., Jaca, C., \& Tanco, M. (2015). Why are companies still struggling to reach higher continuous improvement maturity levels? Empirical evidence from high performance companies. The TQM Journal. 27(3), 316-327.

Kaye, M., \& Anderson, R. (1999). Continuous improvement: the ten essential criteria. International Journal of Quality \& Reliability Management, 16(5), 485-506. http://dx.doi. org/10.1108/02656719910249801.

Lam, M., O’Donnell, M., \& Robertson, D. (2015). Achieving employee commitment for continuous improvement initiatives. International Journal of Operations \& Production Management, 35(2), 201-215. http://dx.doi. org/10.1108/IJOPM-03-2013-0134.

Teare, R., \& Monk, S. (2002). Learning from change. International Journal of Contemporary Hospitality Management, 14(7), 334-341. http://dx.doi. org/10.1108/09596110210440620.

Vermulm, R., \& Erber, F. (2002). Estudo da competitividade de cadeias integradas ao Brasil: impacto das zonas de livre comércio. Campinas: MDIC/MCT-IE/UNICAMP.

Wruck, K. H., \& Jensen, M. C. (1998). The two key principles behind effective TQM program. European Financial Management, 4(3), 401-423. http://dx.doi. org/10.1111/1468-036X.00073.

Wu, C. W., \& Chen, C. L. (2006). An integrated structural model toward successful continuous improvement activity. Technovation, 26(5-6), 697-707. http://dx.doi. org/10.1016/j.technovation.2005.05.002.

Yin, R. K. (2002). Case study research: design and methods. London: Sage Publications. 